\title{
The contribution of helicopter emergency medical services in the pre-hospital care of penetrating torso injuries in a semi-rural setting
}

M. Gavrilovski ${ }^{*}$ DD, J. E. Griggs ${ }^{1,2}$, E. ter Avest ${ }^{1,3}$, R. M. Lyon ${ }^{1,2}$ and on behalf of Air Ambulance Kent Surrey Sussex

\begin{abstract}
Background: Although the merit of pre-hospital critical care teams such as Helicopter Emergency Medical Services (HEMS) has been universally recognized for patients with penetrating torso injuries who present with unstable physiology, the potential merit in patients initially presenting with stable physiology is largely undetermined. The ability to predict the required pre-hospital interventions patients may have important implications for HEMS tasking, especially when transport times to definitive care are prolonged.

Methods: We performed a retrospective cohort study of patients who sustained a penetrating torso injury and were attended by the Air Ambulance Kent Surrey Sussex (AAKSS) over a 6-year period. Primary outcome was defined as the percentage of patients with penetrating torso injuries requiring HEMS-specific interventions anytime between HEMS arrival and arrival at hospital. Secondary outcomes were the association of individual patient- and injury characteristics with the requirement for HEMS interventions.

Results: During the study period 363 patients met inclusion criteria. 90\% of patients were male with a median age of 30 years. 99\% of penetrating trauma incident occurred more than 10-min drive from a Major Trauma Centre (MTC). Presenting GCS was $>13$ in 83\% of patients. Significant hemodynamic- or ventilatory compromise was present in more than $25 \%$ of the patients. Traumatic cardiac arrest was present in 34 patients (9.4\%), profound hypotension with SBP $<80 \mathrm{mmHg}$ in $30(8.3 \%)$ and oxygen saturations $<92 \%$ in 30 (8.3\%). A total of $121 \mathrm{HEMS}-$ specific interventions were performed. Although HEMS-specific interventions were associated with presenting physiology (TCA OR 1.75 [1.41-2.16], SBP < 80 mmHg (OR 1.40 [1.18-1.67] and $\mathrm{SpO}_{2}<92 \%$ (OR 1.39 [1.17-1.65], a minority of the patients presented initially with stable physiology but deteriorated on route to hospital and required HEMS interventions $(n=9,3.3 \%)$.
\end{abstract}

\footnotetext{
* Correspondence: MajaG@aakss.org.uk

${ }^{1}$ Air Ambulance Kent Surrey Sussex Trust, Rochester City Airport, Maidstone Road, Kent ME5 9SD, UK

Full list of author information is available at the end of the article
}

(C) The Author(s). 2021 Open Access This article is licensed under a Creative Commons Attribution 4.0 International License, which permits use, sharing, adaptation, distribution and reproduction in any medium or format, as long as you give appropriate credit to the original author(s) and the source, provide a link to the Creative Commons licence, and indicate if changes were made. The images or other third party material in this article are included in the article's Creative Commons licence, unless indicated otherwise in a credit line to the material. If material is not included in the article's Creative Commons licence and your intended use is not permitted by statutory regulation or exceeds the permitted use, you will need to obtain permission directly from the copyright holder. To view a copy of this licence, visit http://creativecommons.org/licenses/by/4.0/ The Creative Commons Public Domain Dedication waiver (http://creativecommons.org/publicdomain/zero/1.0/) applies to the data made available in this article, unless otherwise stated in a credit line to the data. 
Conclusion: HEMS teams provide potentially important contribution to the pre-hospital treatment of patients with penetrating torso injuries in rural and semi-rural areas, especially when they present with unstable physiology. A certain degree of over-triage is inevitable in these patients, as it is hard to predict which patients will deteriorate on route to hospital and will need HEMS interventions. The results of this study showing a potentially predictable geographical dispersion of penetrating trauma could inform multi-agency knife crime prevention strategy.

Keywords: Penetrating trauma, County lines, HEMS, Pre-hospital

\section{Background}

Trauma can be a time sensitive condition [1]. This is reflected by the golden hour concept dating from 1975, which is still ingrained in trauma systems and national field triage guidelines used by emergency medical services [2]. As a result, Emergency Medical Services (EMS) often try to minimize scene time for trauma patients [3, 4], even though most studies have not demonstrated a clear association between pre-hospital time and patient outcome [2, 5-7]. For some subgroups of trauma patients however, prolonged scene times have been associated with an increased mortality [8].

One of these subgroups comprises of patients with penetrating trauma to the torso. These patients pose a significant challenge to pre-hospital care providers, as bleeding from underlying vascular structures is noncompressible [9]. In the main, these patients benefit from expeditious transport to a specialist trauma centre $[3,10]$. This is especially true when advanced critical care teams with the capability to perform pre-hospital interventions such as blood product transfusion, thoracostomies or thoracotomy are not immediately available $[4,11]$.

However, patients with penetrating trauma of the torso are a highly heterogenous group of patients [12]. Some patients will have critical injuries resulting in rapid clinical deterioration (tension pneumothorax, cardiac tamponade or a large artery laceration). These patients are likely to deteriorate before the arrival of critical care teams. Most will benefit from critical interventions on scene, and all of them will benefit from expedited transport to definitive care [10]. Other patients, however, do not demonstrate such a rapid deterioration as a result of their injuries, but given the extent and location of their injuries still have the potential to do so [13].

Although the merit of critical care teams such as Helicopter Emergency Medical Services (HEMS) has been recognized for patients with penetrating torso injuries who present with unstable physiology, the potential merit in patients initially presenting with stable physiology is largely undetermined. Being able to predict the clinical course of these patients may have important implications for the tasking of HEMS teams, especially when transport times to definitive care are prolonged [8].

Previous research has demonstrated that clinical examination alone is a poor predictor of both severity and depth of penetrating injuries $[14,15]$. Therefore, in this study we aim to describe the patient demographics and clinical interventions required in patients with penetrating torso injuries treated by a semi-rural HEMS service.

\section{Methods \\ Study design and setting}

A retrospective cohort study was performed of all patients with penetrating torso injuries attended by Air Ambulance Kent Surrey Sussex (AAKSS) during a 6year period (1 January 2014 to 31 December 2019). AAKSS is a HEMS service covering three counties in the southeast of England with a resident population of 4.5 million and transient population of up to 8 million. Doctor-paramedic teams respond in either a helicopter or response car from one base. The service attends approximately 2000 patients per year. Most patients attended by the HEMS service are first seen by a ground ambulance crew and/or a critical care paramedic.

A Critical Care Paramedic and HEMS dispatcher screen and task the critical care resource simultaneously with a ground ambulance crew/critical care paramedic from the Emergency Operations Centre. The tasking algorithm was devised internally, and is previously published [16]. Activations are categorised as: immediate (Grade 1), interrogated (Grade 2) or crew request (Grade 3 and 4). Immediate dispatch is triggered by predetermined criteria. Interrogated dispatch is triggered where subsequent clinical information is reviewed, and HEMS dispatch agreed. Both immediate and interrogate dispatches are based on mechanism of injury, clinical condition of the patient and geographical location. A crew request can be activated by crews on scene.

Penetrating trauma attracts a grade 1 dispatch when there is indication of a persistent decreased level of consciousness and/or collapse, or high impact penetrating trauma to the chest with shortness of breath, difficulty in breathing and/or collapse.

\section{Treatment of penetrating injuries and patient disposition} In-line with AAKSS Standard Operating Procedure on penetrating torso trauma, time to definitive care is paramount. When physiology allows, the HEMS team facilitates expedited transfer to definitive care either by 
ground escort or air transfer, without further interventions on scene.

When patients present with shock physiology, both obstructive shock causes are excluded and treated, as is hemorrhagic shock. $\mathrm{FiO}_{2}$ is maximized with a nonrebreather mask, and, if co-operative, the patient will self-ventilate. Tranexamic acid is administered, and where verbal contact is lost, or when the systolic blood pressure (SBP) is $<80 \mathrm{mmHg}$ (when verbal contact is not possible, e.g. in intubated patients), volume therapy with warmed packed red blood cells (PRBC) and freezedried plasma (FDP) is initiated. Up to four units of PRCs are stored in a CRËDO CUBE ${ }^{\mathrm{mm}}$ (Series 4, 21 Insulation 15, VIP Golden Hour) and four units of plasma (Lyoplas) are transfused using a Qinflow ${ }^{\text {tax }}$ fluid warmer. Transfusion is titrated to systolic blood pressure (SBP) and/or Glasgow Coma Score [GCS], aiming for cerebration and/or SBP $>80 \mathrm{mmHg}$. When there is penetrating trauma to chest, abdomen or limbs with loss of cardiac output on scene or on route to hospital, and where tension pneumothorax is excluded, resuscitative thoracotomy is performed if cardiac arrest occurred withing the preceding $10 \mathrm{~min}$.

All patients with head, neck, chest, axillae and groin wounds are triaged to an MTC irrespective of clinical state. Patients with limb wounds are triaged to a Trauma Unit (TU), unless significant neurovascular compromise is anticipated. A pre-alert to the receiving hospital is made at the discretion of the pre-hospital team in order to trigger a predefined in-hospital major hemorrhage protocol based on presenting pre-hospital clinical signs \& physiology, ensuring blood and clotting factors are immediately available upon arrival $[17,18]$.

\section{Study population}

Patients were eligible for participation in the study if they had sustained a penetrating injury to the torso (chest, abdomen or junctional zones [neck, axilla and groin]) for which they were attended by AAKSS HEMS during the study period. Location of penetrating injury was determined based on the notes entered by the treating physician in mandatory entry fields of the bespoke electronic patient clinical record system (HEMSbase 2.0, Medic One Systems Ltd., UK).

\section{Data acquisition}

The following variables were collected from HEMSbase: demographic descriptors (age [years], gender [male/female]), geographical descriptors [postcode], injury descriptors [injury mechanism, anatomical site of injury, mission timings (time of injury (day [0700-1900] or night [1900-0700], exact 999/112 time, arrival on scene time, scene departure time, arrival at hospital time), patient physiology upon presentation of HEMS (presence of profound hypotension defined as a SBP $<80 \mathrm{mmHg}$ ) and tachycardia (defined as a HR $>100 \mathrm{bpm}$ ), presenting GCS, presenting prehospital Lactate $(\mathrm{mmol} / \mathrm{l}$ ) (if measured), HEMS interventions (finger thoracostomy, intercostal chest drain insertion, blood product administration (PRBC/FDP), pre-hospital emergency anaesthesia [PHEA]), intubation without drugs by HEMS, resuscitative thoracotomy $[\mathrm{RT}]$ ), and patient result (carry in the aircraft [Air], ground escort [GE] with HEMS team, ground assist [GA] with local ambulance crew, discharged from scene or pronounced life extinct (PLE). Thoracostomies are counted per thoracostomy and not reported where a thoracotomy was subsequently performed. To get a better overview of the geographical distribution of penetrating injuries, heat-mapping charts of incidents recorded were generated using Maptive [19].

\section{Clinical endpoints}

The cohort of patients will be subdivided into those requiring HEMS specific interventions and those who didn't. The need for HEMS specific interventions was deemed a worthy surrogate for injury severity, thereby clinical course in our study population.

\section{Primary endpoint}

The percentage of patients with penetrating torso injuries attended requiring specific HEMS interventions anytime between HEMS arrival and presentation in hospital.

\section{Secondary endpoint}

The association of individual patient- and injury characteristics with the requirement for HEMS interventions.

\section{Ethical considerations}

This project met National Institute for Healthcare Research (NIHR, UK) criteria for service evaluation and formal ethical approval was therefore not required. The project was approved by the AAKSS Research \& Development Committee.

\section{Statistical analysis}

Descriptive statistics are given as mean $[95 \% \mathrm{CI}]$ or median [IQR]. Comparisons across groups were made using Fisher's exact test, Mann-Whitney U test and the Student's t-test where appropriate. When three or more groups were present, nominal data were compared using Kruskal-Wallis test. Univariate correlation analysis with calculation of Spearman correlation coefficients was performed to evaluate the association of injury- and patient characteristics with the occurrence of physiology demanding HEMS interventions. Subsequent multivariable logistic regression analyses with calculation of odds ratio's (OR) determined which factors were independently related to the primary outcome measure. A $p$-value < 
0.05 was regarded as statistically significant. All statistical analyses were conducted using SPSS 26.0 for Mac.

\section{Results \\ Study population}

During the study period AAKSS was tasked to 10,169 patients. Nine thousand six hundred seventeen patients (96\%) sustained an injury by blunt trauma or were attended for medical (non-trauma) reasons. Five hundred fifty-two patients were attended as a result of sharp object penetrating trauma, of which 173 were selfinflicted. Sixteen patients out of the remaining 379 had isolated limb injuries, leaving 363 patients with sharp object penetrating torso injury as a result of an assault. Patient inclusion is shown below in Fig. 1 .

\section{HEMS tasking and timings}

Geographical distribution of penetrating trauma over the 6-year study period exhibited a specific pattern which mirrored existing drug trafficking county lines (Fig. 2). The vast majority (99\%) of penetrating trauma occurred more than 10 min drive from an MTC. Overall, the median [IQR] time to scene from 999/112 call was 39 [2950] minutes and the median time to hospital was $1 \mathrm{~h} 30$ [88-97] minutes (Table 1). The HEMS team was quicker on scene during daytime compared to nighttime (37 [19-31] mins vs 41 [20-35], $p=.017$ ), but the overall time to definitive care was not shorter (90 [62-106] mins vs 87 [47-93] mins, $p=.958$ ).

\section{Patient characteristics}

Approximately half of the patients were seen during daytime hours $(n=155,42.7 \%)$ and the other half during night-time operations $(n=208,57.3 \%)$. Most patients were male $(89.8 \%, p<.05)$ and the majority of the patients were relatively young (median age of 30 years [IQR 2342]). Presenting GCS was $>13$ in 301 (82.9\%) of patients. A minority but significant number of patients $(n=34$, 9.4\%) went into TCA either before or after arrival of the HEMS team and 30 patients (8.3\%) exhibited profound hypotension ( $\mathrm{SBP}<80 \mathrm{mmHg}$ ) before arrival in hospital. Respiratory distress was present in a minority of patients, with 30 patients presenting with $\mathrm{SpO}_{2}<92 \%$ (8.3\%) and 32 patients with a RR $>30$ (8.8\%). Lactate levels were measured in 26 patients and were elevated $(>2.0 \mathrm{mmol} / \mathrm{l})$ in the majority $(85 \%)$ (Table 1$)$.

\section{Patient conveyance and disposition}

HEMS conveyed the majority of patients (78.5\%) to hospital. Most patients $(n=210,57.9 \%)$ were conveyed by ground escort, with 75 patients $(20.7 \%)$ being transferred by air. Most patients were conveyed to an MTC, with only a small proportion being triaged to $\mathrm{TU}$ or to a Local Emergency Hospital (LEH). Thirty-one patients were pronounced life extinct (PLE) at the scene (Table 2).

\section{HEMS interventions}

HEMS interventions were performed relatively infrequently. 54 of $363(14.9 \%)$ patients received a total of 121 HEMS interventions. Thoracostomies were performed most often $(n=31)$ with other interventions such as intercostal chest drain insertion, pre-hospital emergency anesthesia (PHEA), blood product administration, thoracotomy, and intubation without drugs being performed less frequently (Table 3 ). The number of patients in whom HEMS interventions were performed was consistent over the 6-year study period $(p=.132)$.

\section{Association of patient- and injury characteristics with the requirement for HEMS interventions}

Patients receiving HEMS interventions required these based on presenting physiology. They had either a compromised circulation (TCA or SBP $<80 \mathrm{mmHg}, n=43$ ), or isolated compromised ventilation $(\mathrm{RR}>30$ or $\mathrm{SpO} 2<$ $92 \%$ with suspicion of significant pneumothorax, $n=2$ ). 27 out of 34 patients in TCA and 16 out of the 30 patients presented with hypotension $(\mathrm{SBP}<80 \mathrm{mmHg}$ ) and received one or more HEMS interventions (Table 4). Fourteen patients presenting to the HEMS team with hypovolemic shock were not anesthetized and were cerebrating well, and therefore, as per AAKSS SOP, did not receive blood products from the attending HEMS team. All patients presenting with significant respiratory distress due to a pneumothorax received a pre-hospital chest drain. The majority of patients without circulatoryor ventilatory compromise did not need HEMS interventions. Nine patients, however, initially presented with stable physiology but needed HEMS interventions on route to hospital. On case review, 4 patients required blood product transfusion, either PRBC and/or FDP, 3 required placement of an intercostal chest drain, 1 patient required PHEA and 1 patient deteriorated to TCA requiring a RT and blood product transfusion.

In univariate correlation analysis, male gender $(r=$ $.248, p<.001)$, TCA $(r=.513 p<.001)$, presence of hypotension- $(r=.303, p<.001)$, tachycardia $(r=.286$ $(p<.001)$, reduced oxygen saturation $(<92 \%)(r=.288$, $p=.001)$ and respiration rate $(r=.408, p=.001)$ were associated with one or more HEMS interventions being performed.

In multivariable logistic regression analysis TCA (OR 1.751 [1.41-2.16], hypotension (OR 1.40 [1.18-1.67] and $\mathrm{SpO}_{2}<92 \%$ (OR 1.39 [1.17-1.65] were independent physiological findings associated with the requirement of HEMS interventions on scene or on route to hospital. 


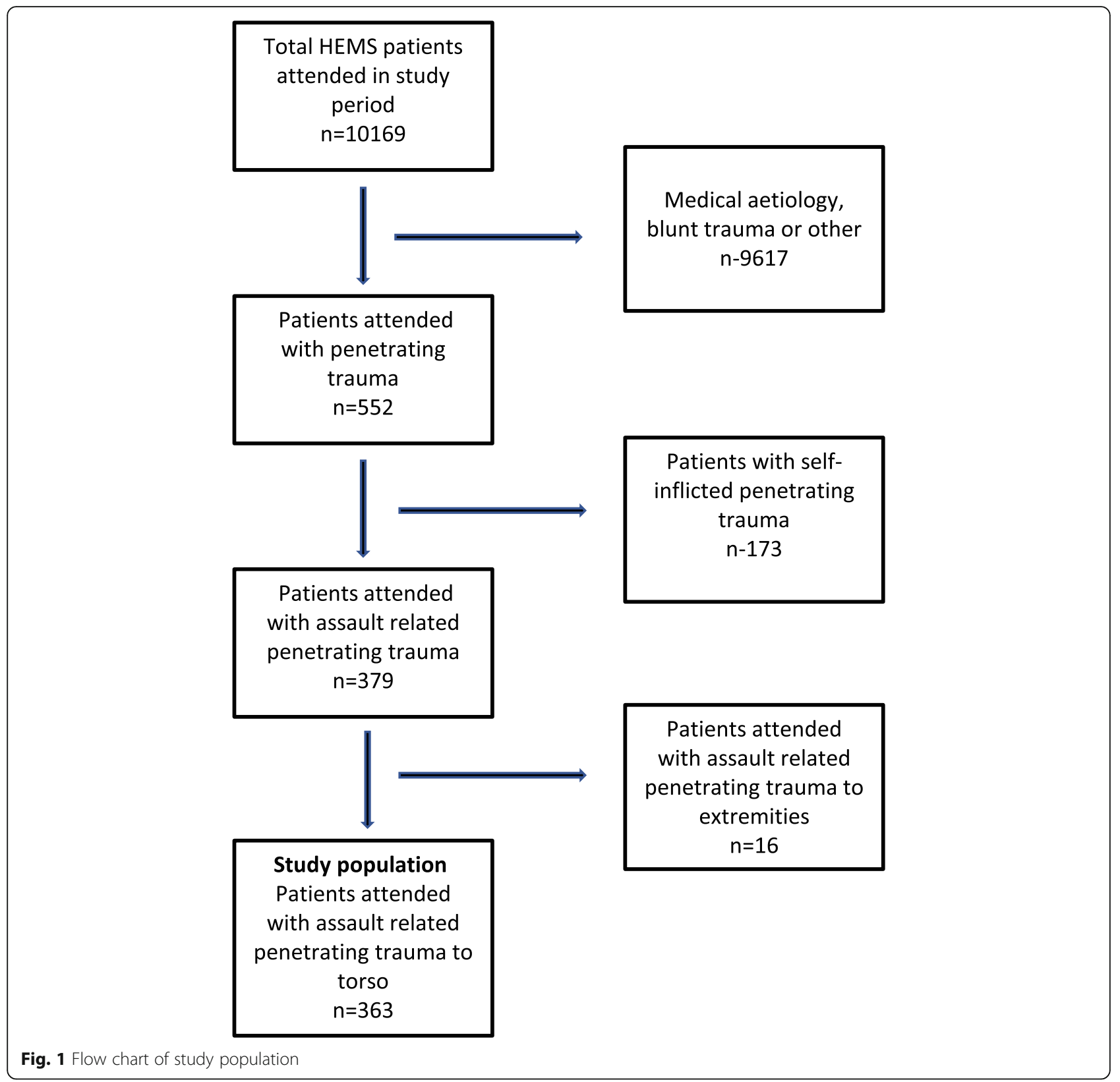

\section{Discussion}

Penetrating trauma has been a substantial part of the trauma workload in urban areas in the UK for the last decade [20]. However, the incidence of penetrating trauma is increasing in both rural and semi-rural regions. In this observational study performed in a semirural HEMS service, we demonstrate that around $15 \%$ of the patients with penetrating torso injuries attended by HEMS require one or more HEMS specific time-critical interventions in the pre-hospital setting, whereas $85 \%$ do not require interventions. Unsurprisingly, presenting physiology was associated with the need for HEMS interventions. The majority of the patients in traumatic cardiac arrest received HEMS interventions, whereas HEMS interventions were performed in around 50\% of the patients presenting with hypovolemic shock physiology, and in all patients presenting with isolated severe respiratory distress without hypotension.

In this study, we report a unique geographical distribution of penetrating torso trauma cases attended by HEMS, largely aligning to the drug-trafficking county lines [21, 22]. The multi-agency Kent and Medway Gang Strategy (2018-2021) warn of steadily increasing gang operations across the Kent and Medway region, originating from London-based individuals venturing into the region for 'homegrown' gangs. Given the proximity to 


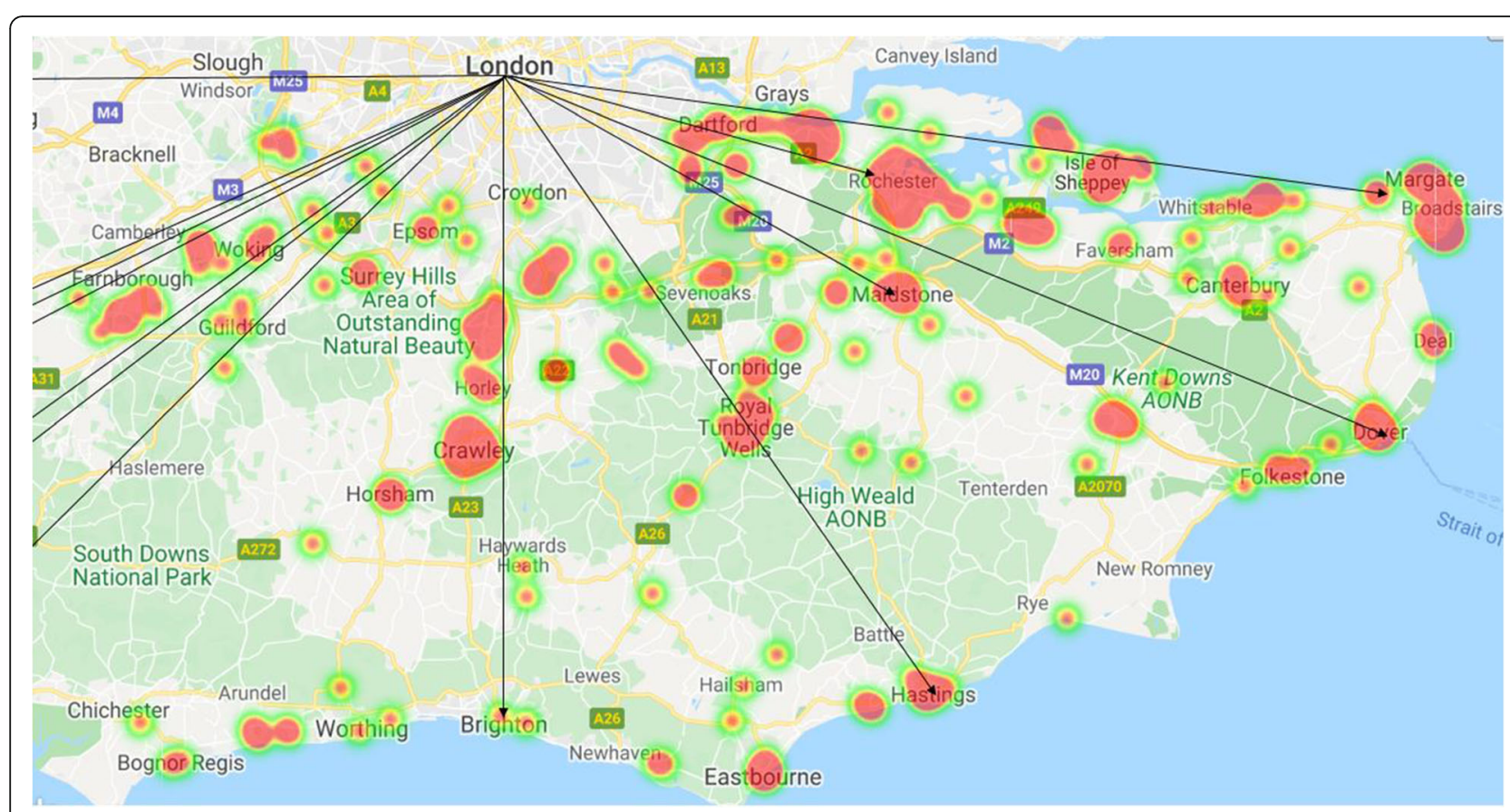

Fig. 2 Heat map showing geographical distribution of penetrating trauma over a 6-year period in relation to drug-trafficking county lines, for the region served by AAKSS (southeast England). Red shading depicts areas of increased incidence of penetrating injuries attended by AAKSS across the geographical region. Black arrows represent the county lines drug supply routes across southeast England, stemming from the English Channel towards London. County lines are adapted from Coomber and Moyle (2018)

London, the counties of Surrey and Sussex (predominantly in those areas with the highest socioeconomic deprivation) are liable to the same trend [23, 24]. An appreciation of the geographical distribution of penetrating trauma in relation to diurnal patterns is imperative to not only multi-agency knife violence prevention and education but also policing and safeguarding the needs of the vulnerable $[25,26]$. AAKSS considers this evidence-base essential from which to contribute valuable preventative educational strategies.

Interestingly, we could not establish an association between the time elapsed from 999/112 call to attendance and the need for HEMS interventions. This likely reflects the spectrum of pathology resulting from penetrating injuries. Most patients do not have significant injuries to vascular structures or vital organs and will remain cardiovascularly stable until presentation at hospital. A small group will have major arterial injuries and will almost universally need HEMS interventions on scene, even when they are seen very shortly after their injury. Finally, a third group will have ongoing venous bleeding, with a potential to deteriorate in the pre-hospital phase of their injury. It is likely that these patients are underrepresented in the current cohort, and thereby obscure any association between the time elapsed from 999/112 call to HEMS attendance and the need for HEMS interventions.

In our study population, 9 patients initially presented without significant haemodynamic or ventilatory compromise, but deteriorated during transit to hospital and required advanced medical intervention, ranging from inter-costal chest drain insertion or blood product transfusion to PHEA and resuscitative thoracotomy. Although this is a small percentage of all patients presenting without significant haemodynamic or ventilatory compromise, the interventions performed may be lifesaving in nature given the long average distance from the nearest MTC.

A certain degree of over-triage of patients initially presenting without significant hemodynamic- or ventilatory compromise by HEMS teams in this respect, is almost inevitable. Previous studies have demonstrated that the accuracy of clinical examination to establish the degree of bleeding and potential for internal damage after penetrating injury is poor $[14,27,28]$. Our clinical judgement in these patients is often obscured, as the scene of the incident is often not witnessed (making it hard to estimate the amount of blood loss), and the physiological response to blood loss in the patients may differ from non-penetrating injuries. Especially with peritoneal breeching, relative bradycardia may be present, obscuring the normal baroreceptor response. Therefore, all torso stab wounds should be considered as invasive until imaging is complete [14] and HEMS teams should have a low threshold to escort these patients to hospital, irrespective of their physiological state. However, given the small proportion of hemodynamically stable patients 
Table 1 Patient and injury descriptors of patients with penetrating torso injuries attended by AAKSS during a 6-year period stratified by the need for HEMS specific interventions

\begin{tabular}{|c|c|c|c|c|}
\hline & ALL & HEMS interventions & No HEMS interventions & $P$ value \\
\hline TOTAL $[n, \%]$ & 363 & 54 [14.9] & $309[85.1]$ & \\
\hline \multicolumn{5}{|l|}{ Demographics } \\
\hline Male $[n, \%]$ & 326 [89.8]] & $43[13.2]$ & $283[86.8]$ & .349 \\
\hline Age [median, IQR] & $30[23-42]$ & $30[21-44]$ & $31[23-42]$ & .531 \\
\hline$<=16[n, \%]$ & $11[3.0]$ & $2[18.2]$ & $9[81.8]$ & .272 \\
\hline $17-25[n, \%]$ & $114[31.4]$ & $15[13.2]$ & $99[86.8]$ & .336 \\
\hline $26-45[n, \%]$ & $164[45.2]$ & $19[11.6]$ & $145[88.4]$ & .100 \\
\hline $46-65[n, \%]$ & $60[16.5]$ & $13[16.7]$ & $47[78.3]$ & 1.00 \\
\hline$>65[n, \%]$ & 14 [3.9] & $5[35.7]$ & $9[64.3]$ & .132 \\
\hline \multicolumn{5}{|l|}{ Job descriptors } \\
\hline Daytime [0700-1900] [n,\%] & 155 & 29 [18.7] & $126[81.3]$ & .009 \\
\hline Night-time [1900-0700] [n,\%] & 208 & $25[12.0]$ & $183[88.0]$ & .009 \\
\hline 999-scene [hours:mins] & $00: 39$ & $00: 37$ & $00: 39$ & .583 \\
\hline 999-hospital (hours:mins) & $01: 30$ & 01:47:00 & 01:29:00 & .283 \\
\hline \multicolumn{5}{|l|}{ Presenting physiology } \\
\hline GCS [median] & 15 & 4 & 15 & \\
\hline $14-15$ & $301[82.9]$ & $20[6.6]$ & $281[93.4]$ & $<.001$ \\
\hline $9-13$ & $12[3.3]$ & $5[41.7]$ & $7[58.3]$ & $<.001$ \\
\hline $3-8$ & $35[9.6]$ & $28[80.0]$ & $7[20.0]$ & $<.001$ \\
\hline TCA $[n, \%]$ & $34[9.4]$ & $27[79.4]$ & $7[20.6]$ & $<.001$ \\
\hline Hypotension (SBP < 80 mmHg) [n,\%] & $30[8.3]$ & $16[53.3]$ & $14[46.7]$ & $<.001$ \\
\hline Tachycardia (HR > 100 BPM) [n,\%] & $111[30.6]$ & $17[15.3]$ & $94[84.7]$ & $<.001$ \\
\hline $\mathrm{SpO} 2<92 \%[n, \%]$ & $30[8.3]$ & $12[40.0]$ & $18[60.0]$ & $<.001$ \\
\hline $\mathrm{RR}>30[\mathrm{n}, \%]$ & $32[8.8]$ & $10[31.25]$ & $22[68.75]$ & $<.001$ \\
\hline Lactate $(\mathrm{mmol} / \mathrm{l}[\mathrm{n}, \%])$ & $26[7.2]$ & $4[15.4]$ & $22[84.6]$ & .907 \\
\hline
\end{tabular}

GCS Glasgow Coma Score; TCA Traumatic Cardiac Arrest; $\mathrm{SpO}_{2}$ Oxygen saturation; $R R$ respiration rate

Table 2 HEMS conveyance and patient disposition of patients with penetrating torso injuries

\begin{tabular}{|c|c|c|c|c|}
\hline & ALL & HEMS interventions & No HEMS interventions & $P$ value \\
\hline Patient conveyance & 363 & 54 & 309 & \\
\hline Air & $75[20.7]$ & $12[16.0]$ & $63[80.4]$ & .470 \\
\hline Ground escort & 210 [57.9] & $18[8.6]$ & $192[91.4]$ & .002 \\
\hline Ground assist & $47[12.9]$ & $0[0]$ & $47[100.0]$ & $<.001$ \\
\hline PLE & $31[8.5]$ & $24[77.4]$ & 7 [22.6] & $<.000$ \\
\hline \multicolumn{5}{|l|}{ Patient disposition } \\
\hline MTC & $293[80.7]$ & $29[9.9]$ & $264[90.1]$ & .001 \\
\hline TU & $31[8.6]$ & $1[3.2]$ & $30[96.8]$ & .006 \\
\hline LEH & $3[0.8]$ & $0[0]$ & $3[100.0]$ & .557 \\
\hline PLE & $31[8.6]$ & $24[77.4]$ & $7[22.6]$ & .000 \\
\hline Self-discharged & $5[1.4]$ & $0[0]$ & 5 [100.0] & .001 \\
\hline
\end{tabular}

PLE Pronounced Life Extinct; MTC Major Trauma Centre; TU Trauma Unit; LEH Local Emergency Hospital 
Table 3 HEMS specific interventions performed in patients with penetrating torso injuries

\begin{tabular}{ll}
\hline HEMS Interventions & $\mathbf{n = 1 2 1}$ \\
\hline Thoracostomy n[\%] & $31[25.6]$ \\
Intercostal chest drain n[\%] & $9[7.4]$ \\
PHEA n[\%] & $10[8.3]$ \\
Blood products n[\%] & $34[28.1]$ \\
PRBC (units) & 76 \\
FDP (units) & 47 \\
Thoracotomy n[\%] & $18[14.9]$ \\
Intubation, without drugs n[\%] & $19[15.7]$ \\
\hline PHEA pre-hospital emergency anaesthesia; PRBC packed red blood cells; FDP \\
freeze-dried plasma
\end{tabular}

who need a HEMS intervention, the clinical team must perform a risk assessment, to include potential for clinical deterioration. The outcome of such a risk assessment is likely dependant on: availability of HEMS and/or other critical care teams, suspected transport time to hospital, and exact anatomical location of injury. There is also a trend towards avoiding pre-hospital anaesthesia in this group of patients, in favour of blood product transfusion and rapid transport to hospital. Early intubation in the hypovolaemic patient, particularly the switch to positive pressure ventilation, can lead to rapid cardiovascular collapse in some patients.

Over half of the penetrating trauma incidents attended were within a night operational context. This is in line with previous work reporting an increased rate of victims of assault and self-harm compared to daylight hours [29]. Night-time availability of HEMS and the availability of ad-hoc or pre-surveyed sites contributes to expedited care for these patients [29]. In the present study however, the latter could not be demonstrated as during the study period helipad access to the MTC's was restricted to daylight operation hours only, and therefore patients were universally ground escorted by the HEMS teams during night operational hours.
HEMS teams are likely not only provide advanced clinical skills, but also to support advanced clinical decision-making in terms of triage and transport. This is hard to substantiate and not measured in the current study. However, Cowley et al. reported that patients with penetrating injuries presenting in the region of our HEMS service were more likely triaged to an MTC when attended by an enhanced care team compared to standard ground ambulance crews (OR 7.59, 3.70-15.37, $p<$ 0.0001) [4] . Although this could be attributed to a selection bias regarding injury burden and injury severity, it is likely that due to clinical experience these teams are perhaps increasingly aware of underlying injuries, and the potential for deterioration on route to hospital. Enhanced pre-hospital care practitioners may expedite transport to hospital, even when ground escorting patients, as they have the capability to intervene during transit if necessary.

\section{Limitations}

Our study has several limitations, mostly inherent to the study design. First, our population studied is confined to patients attended by HEMS, and not to the wider population of patients with penetrating torso injuries. However, as penetrating torso injury is a dispatch criterium for AAKSS HEMS, it is unlikely that many patients have been missed during the study period. Further, our study results cannot automatically be extrapolated to other geographical regions with different transport times and/ or availability of $24 / 7$ HEMS. We are conscious that nearly half of the HEMS interventions are performed in those patients pronounced life extinct. Finally, we have no information on the definitive injuries and/or outcome of our patients. Therefore, it remains speculative that the HEMS interventions performed have contributed to a favourable outcome in our patients, or if those transported in a hemodynamically stable condition without HEMS interventions possibly deteriorated at a later stage. The dispatch elements, data from the ground ambulance prior to arrival of HEMS and long term patient

Table 4 Presenting physiology of patients requiring HEMS-specific interventions for penetrating torso injuries

\begin{tabular}{llll}
\hline Presenting physiology & Total number of patients & Patients received interventions & Total number of interventions \\
\hline & $\mathrm{n}[\%]$ & $\mathrm{n}[\%]$ & $\mathrm{n}[\%]$ \\
Total & 363 & 54 & 121 \\
$\begin{array}{l}\text { Uncompromised circulation and ventilation } \\
\text { Compromised circulation }\end{array}$ & $272[74.9]$ & $9[16.7]$ & $13[10.7]$ \\
$\quad T C A$ & $34[9.4]$ & $27[50.0]$ & $70[57.9]$ \\
$S B P<80 \mathrm{mmHg}$ & $30[8.3]$ & $16[29.6]$ & $36[29.8]$ \\
Compromised ventilation (without compromised circulation) & $27[7.4]$ & $2[3.7]$ & $2[1.6]$ \\
\multicolumn{1}{l}{ Isolated $R R>30$ or $\mathrm{SpO}_{2}<92 \%$} & &
\end{tabular}

$T C A$ traumatic cardiac arrest; SBP systolic blood pressure; $R R$ respiratory rate 
outcome were beyond the reach of this initial study, however this is planned for a future project.

\section{Conclusion}

HEMS teams provide a potentially important contribution to the pre-hospital treatment of patients with penetrating torso injuries in rural and semi-rural areas, especially when they present with unstable physiology. A certain degree of over-triage is inevitable in these patients, as it is hard to predict which patients will deteriorate on route to hospital and will need HEMS interventions. The results of this study showing a potentially predictable geographical dispersion of penetrating trauma could inform multi-agency knife crime prevention strategy.

\begin{abstract}
Abbreviations
HEMS: Helicopter emergency medical service; UK: United Kingdom; AAKS S: Air ambulance kent surrey sussex; MTC: Major trauma centre; GCS: Glasgow coma scale; SBP: Systolic blood pressure; TCA: Traumatic cardiac arrest; $\mathrm{SpO}_{2}$ : Oxygen saturation; EMS: Emergency medical services. $\mathrm{FiO}_{2}$ : Fraction of inspired oxygen; PRBC: Packed red blood cells; FDP: Freezedried plasma; TU: Trauma unit; PHEA: Pre-hospital emergency anaesthesia; RT: Resuscitative thoracotomy; GE: Ground escort; GA: Ground assist; PLE: Pronounced life extinct; HR: Heart rate; RR: Respiratory rate; LEH: Local emergency hospital
\end{abstract}

\section{Acknowledgements}

We acknowledge the University of Surrey for their ongoing support.

\section{Authors' contributions}

All authors were involved in the study design. MG and JG collected and analysed the data. All authors contributed to writing the manuscript. All authors read and approved the final manuscript.

\section{Funding}

No funding was used to support this study.

\section{Availability of data and materials}

The datasets used and/or analysed during the current study are available from the corresponding author on reasonable request.

\section{Declarations}

Ethics approval and consent to participate

The project was internally approved by the AAKSS Research and Development Committee and registered with the University of Surrey. Data collection was anonymised and confidential and stored on electronic devices with technical encryption.

\section{Consent for publication}

Not applicable.

\section{Competing interests}

MG, JG, ETA and RL are all employees of Air Ambulance Kent Surrey Sussex. There were no financial or non-financial conflicts of interest.

\section{Author details}

${ }^{1}$ Air Ambulance Kent Surrey Sussex Trust, Rochester City Airport, Maidstone Road, Kent ME5 9SD, UK. ${ }^{2}$ Department of Health Sciences, University of Surrey, Guildford GU2 7XH, UK. ${ }^{3}$ University Medical Center Groningen, Department of Emergency Medicine, University of Groningen, Groningen, The Netherlands.
Received: 2 April 2021 Accepted: 26 July 2021

Published online: 04 August 2021

\section{References}

1. Chen X, Guyette FX, Peitzman AB, Billiar TR, Sperry JL, Brown JB. Identifying patients with time-sensitive injuries: association of mortality with increasing prehospital time. J Trauma Acute Care Surg. 2019;86(6):1015-22. https://doi. org/10.1097/TA.0000000000002251.

2. Newgard CD, Schmicker RH, Hedges JR, Trickett JP, Davis DP, Bulger EM, et al. Emergency medical services intervals and survival in trauma: assessment of the 'golden hour' in a North American prospective cohort. Ann Emerg Med. 2010;55(3):235-246.e4.

3. Brown JB, Rosengart MR, Forsythe RM, Reynolds BR, Gestring ML, Hallinan WM, et al. Not all prehospital time is equal: influence of scene time on mortality. J Trauma Acute Care Surg. 2016;81(1):93-100. https://doi.org/10.1 097/TA.0000000000000999.

4. Cowley A, Durham M, Aldred D, Crabb R, Crouch P, Heywood A, et al. Presence of a pre-hospital enhanced care team reduces on scene time and improves triage compliance for stab trauma. Scand J Trauma Resusc Emerg Med. 2019;27(1):86. https://doi.org/10.1186/s13049-019-0661-z.

5. Lerner EB, Moscati RM. The golden hour: scientific fact or medical "urban legend"? Acad Emerg Med. 2001;8(7):758-60. https://doi.org/10.1111/j.1 553-2712.2001.tb00201.x

6. Petri RW, Dyer A, Lumpkin J. The effect of prehospital transport time on the mortality from traumatic injury. Prehospital Disaster Med. 1995;10(1):24-9. https://doi.org/10.1017/S1049023X00041625.

7. Pepe PE, Wyatt CH, Bickell WH, Bailey ML, Mattox KL. The relationship between total prehospital time and outcome in hypotensive victims of penetrating injuries. Ann Emerg Med. 1987 Mar;16(3):293-7. https://doi. org/10.1016/S0196-0644(87)80174-9.

8. Pham H, Puckett Y, Dissanaike S. Faster on-scene times associated with decreased mortality in Helicopter Emergency Medical Services (HEMS) transported trauma patients Trauma. Surg Acute Care Open. 2017;2:1-5. e000122. https://doi.org/10.1136/tsaco-2017-000122. [cited 2021 Feb 24]

9. Barnard EBG, Smith JE. Non-compressible torso haemorrhage: the new holy grail for further improvement in trauma survival. J R Nav Med Serv. 2018; 104(2):107-14. https://doi.org/10.1136/jrnms-104-107.

10. Beaumont O, Lecky F, Bouamra O, Surendra Kumar D, Coats T, Lockey D, et al. Helicopter and ground emergency medical services transportation to hospital after major trauma in England: a comparative cohort study. Trauma Surg Acute Care Open. 2020;5(1):e000508. https://doi.org/10.1136/tsaco-202 0-000508.

11. Ruelas OS, Tschautscher CF, Lohse CM, Sztajnkrycer MD. Analysis of Prehospital scene times and interventions on mortality outcomes in a National Cohort of penetrating and blunt trauma patients. Prehospital Emerg Care Off J Natl Assoc EMS Physicians Natl Assoc State EMS Dir. 2018; 22(6):691-7.

12. Lozano JD, Munera F, Anderson SW, Soto JA, Menias CO, Caban KM Penetrating wounds to the torso: evaluation with triple-contrast multidetector CT. RadioGraphics. 2013;33(2):341-59. https://doi.org/10.1148/ rg.332125006.

13. Calhoon JH, Trinkle JK. Pathophysiology of chest trauma. Chest Surg Clin N Am. 1997;7(2):199-211.

14. Augustin P, Guivarch E, Pellenc Q, Castier Y, Boudinet S, Tanaka S, et al. Performance of pre-hospital evaluations in ruling out invasive chest stab wounds. Scand J Trauma Resusc Emerg Med. 2020;28(1):33. https://doi.org/1 0.1186/s13049-020-00725-w.

15. Kong W, Sartorius B, Clarke DL. The accuracy of physical examination in identifying significant pathologies in penetrating thoracic trauma. Eur J Trauma Emerg Surg Off Publ Eur Trauma Soc. 2015;41(6):647-50. https://doi. org/10.1007/s00068-014-0484-6.

16. Munro S, Joy M, de Coverly R. et al. A novel method of non-clinical dispatch is associated with a higher rate of critical Helicopter Emergency Medical Service intervention. Scand J Trauma Resusc Emerg Med. 2018;26(1):84 https://doi.org/https://doi.org/10.1186/s13049-018-0551-9

17. Rehn M, Weaver A, Brohi K, Eshelby S, Green L, Røislien J, et al. Effect of PreHospital Red Blood Cell Transfusion on Mortality and Time of Death in Civilian Trauma Patients. Shock [Internet]. 2018 May 31 [cited 2018 Jun 1]; Publish Ahead of Print. Available from: https://journals.lww.com/shockjourna //Abstract/publishahead/Effect_of_Pre_Hospital_Red_Blood_Cell_Tra nsfusion.97840.aspx 
18. Weaver A, Eshelby S, Norton J, Lockey D. The introduction of on-scene blood transfusion in a civilian physician-led pre-hospital trauma service. Scand J Trauma Resusc Emerg Med. 2013;21(Suppl 1):S27. https://doi.org/1 0.1186/1757-7241-21-S1-S27.

19. Heat Map Generator - Create a Custom Heat Map [Internet]. Maptive. [cited 2021 Feb 24]. Available from: https://www.maptive.com/feature/heat-ma pping-tool/.

20. Vulliamy P, Faulkner M, Kirkwood G, West A, O'Neill B, Griffiths MP, et al. Temporal and geographic patterns of stab injuries in young people: a retrospective cohort study from a UK major trauma Centre. BMJ Open. 2018; 8(10):e023114. https://doi.org/10.1136/bmjopen-2018-023114.

21. Williams AG, Finlay F. County lines: how gang crime is affecting our young people. Arch Dis Child. 2019;104(8):730-2. https://doi.org/10.1136/a rchdischild-2018-315909.

22. Coomber R, Moyle L. The changing shape of street-level heroin and crack supply in England: commuting, holidaying and cuckooing drug dealers across 'county lines'. Br J Criminol. 2018;58(6):1323-42. https://doi.org/10.1 093/bjc/azx068.

23. Sethi S, World Health Organization, editors. European report on preventing violence and knife crime among young people. Copenhagen, Denmark: World Health Organization; 2010. p. 102.

24. Glover Williams A, Finlay F, County lines: how gang crime is affecting our young people. Arch Dis Child. 2019;104:730-2.

25. Office of National Statistics. Crime in England and Wales: year ending December 2019. https://www.ons.gov.uk/peoplepopulationandcommunity/ crimeandjustice/bulletins/crimeinenglandandwales/yearendingdecember201 9\#knife-or-sharp-instrument-offences. Accessed 9 July 2020.

26. Melling L, Lansdale N, Mullassery D, Taylor-Robinson D, Jesudason EC Penetrating assaults in children: often non-fatal near-miss events with opportunities for prevention in the UK. Injury. 2012;43(12):2088-93. https:/ doi.org/10.1016/j.injury.2012.03.020.

27. Onat S, Ulku R, Avci A, Ates G, Ozcelik C. Urgent thoracotomy for penetrating chest trauma: analysis of 158 patients of a single center. Injury. 2011;42(9):900-4. https://doi.org/10.1016/j.injury.2010.02.004

28. Wormald PJ, Knottenbelt JD, Linegar AG. A triage system for stab wounds to the chest. South Afr Med J Suid-Afr Tydskr Vir Geneeskd. 1989;76(5):2112.

29. Curtis L, Salmon M, Lyon RM. The impact of helicopter emergency medical service night operations in south East England. Air Med J. 2017 Dec;36(6): 307-10. https://doi.org/10.1016/j.amj.2017.06.005.

\section{Publisher's Note}

Springer Nature remains neutral with regard to jurisdictional claims in published maps and institutional affiliations.

Ready to submit your research? Choose BMC and benefit from:

- fast, convenient online submission

- thorough peer review by experienced researchers in your field

- rapid publication on acceptance

- support for research data, including large and complex data types

- gold Open Access which fosters wider collaboration and increased citations

- maximum visibility for your research: over $100 \mathrm{M}$ website views per year

At $\mathrm{BMC}$, research is always in progress.

Learn more biomedcentral.com/submissions 